\title{
Can Profit-shifting be Resolved by Penalization?"
}

\author{
Tomáš BUUS ${ }^{*}-$ Jaroslav BRADA**
}

Due to the increasing role of MNEs and their impact on national welfare, on effectiveness of economic policies and on quality of our lives, we should have tremendous interest to clearly and well understand how to deal with transfer pricing issues. Compared to macroeconomic issues, equity premium or many other microeconomic issues, transfer pricing gets much less attention than it deserves. Theory and practice are quite contrary about what shall be optimal transfer price equal to. Both older and new literature on transfer pricing is mostly based on considering the best transfer price on the level of marginal cost. In the first line we could mention pioneering articles (Schmallenbach, 1908) and (Hirshleifer, 1956). Newer works like (Gatti - Grinell - Jensen, 1997), (Baldenius Melumad - Reichelstein, 2004) or (Pappas - Brigham - Hirschey, 1983) still consider marginal cost of supplying division as the best solution of the transfer pricing problem. In contrary to the literature on corporate finance and microeconomics there is (often implied) assumption emerging in articles and books aimed on tax issues of transfer pricing. Transfer Pricing Guidelines for Multinational Enterprises and Tax Administrations could serve as an example. Methods of treating transfer prices based on comparable prices advised by OECD to be used by particular national tax authorities are derived from market prices, which only in few extraordinary cases could be on the level of marginal cost. Arms-length price can be rather viewed as an average or range of market prices. Under these conditions almost no multinational or MNE optimizing only its output (not tax paid) would meet requirements of tax authorities because it would set the transfer price as marginal cost of

\# This article is processed as an output of a research project Regulation of Transfer Pricing registered by the Grant Agency under the registration number 402/08/0271.

Ing. Tomáš Buus, Ph.D. - assistant professor; Department of Corporate Finance and Business Valuation, University of Economics, Prague, W. Churchill sq. 4, 13067 Prague, Czech Republic; <buust@vse.cz>.

** Doc. Ing. Jaroslav Brada, Ph.D. - associate professor; Department of Monetary Theory and Policy, University of Economics, Prague, W. Churchill sq. 4, 13067 Prague, Czech Republic; <brada@vse.cz.>. 
supplying division. However, marginal cost is only very rarely equal to market price and distorts resource allocation in MNE. Buus and Brada (2008) elaborate on that and come to a conclusion that the universally suitable transfer price is on average cost of intermediate product.

OECD (2001) transfer pricing guidelines outline several methods of determination of proper transfer price: comparable uncontrolled price, cost + method, comparable resale price method, profit split method, etc. But need for enforcement is common to the approach when the tax authority does not have an instrument, which would MNE drive out of tax-evasive transfer pricing. It is also notable that academic literature does not come to consensus on whether ability to evade tax through transfer pricing will cause "race to the bottom", i.e. to the lowest possible taxation, or "race to the top".

Under the assumption that governments use tax income to provide public goods, i.e. substantial part of public budget is not stolen in manipulated public procurement (like in the Czech republic), increase of tax revenue leads to increase of provision of public goods, which are more efficiently provided by government than by individuals or corporations. If there was only one corporation in the country B, as e.g. (Stöwhase, 2005) or (Amerighi, 2008) or (Raimondos -Møller - Scharf, 2002) assume, then it could not have substantial utility from profitshifting, because this way it would decrease demand for its own products and decrease level of public services, to itself detriment. However, closed systems, as mentioned in the above papers, are not common in real world. We can rather bet on that MNE exploits the fact that decreased government revenues spill across economy and finally will hamper the domestic producers much more than MNE. We come to this statement, because

1. on the supply side MNE pays less taxes per product comparable to purely domestic producer and is able to provide the same product for lower price,

2. with decrease of tax income the overall level of public goods and social security decreases, so that consumers become more pricesensitive,

3. the above two effects are even strengthened by need to tax labor and non-MNE producers more, because MNE evade taxes. 
One could argue that the evaded tax has to end somewhere (in another economy), so that the total effect of existence of low-tax jurisdictions will be weakened. But it can be directly observed that among the richest individuals in each country many have SPVs (special purpose companies) in those low-tax jurisdictions. If it were for a corporation with wide public ownership, profits would get back in increased private consumption. But an individual will not spend much more on private consumption if he/she has 100 million USD or 1 billion USD.

In the real world only two instruments remain to keep the profits where their originated: severe penalty for evading tax or design of tax system, which would let multinationals no advantage of shifting tax base.

We concentrate on model of transfer pricing regulation enforcement in this paper and we would like to answer question, whether is there an optimal penalty for breaking the transfer pricing rules or not. First we set up assumptions and conditions of the model, then we derive optimal solutions for MNE and tax authority in country with the higher (or highest) corporate income tax rate and finally we discuss the results.

\section{Assumptions, model}

We assume that:

1. All agents prefer more money to less, are risk-neutral and prefer the same amount of money earlier rather than later.

2. From 1. it clearly comes that any regulation that would decrease income or increase cost for any individual fails without enforcement.

3. Divisions of MNE are bound to follow common goal, maximization of market value of capital of MNE. Therefore these divisions collaborate to minimize the total amount paid to revenue authorities.

4. Revenue authorities do not cooperate.

5. A proper transfer price $p_{T}$ cannot be exactly determined (rather estimated with some uncertainty), because we cannot find perfectly transactions between unrelated parties perfectly comparable to the ones within MNE. Divisions of MNE do not face the same level of credit risk and risk of costly law suits as the unrelated parties do, 
because MNE headquarters would prevent any harmful dispute that is not necessary.

6. There are 2 divisions of MNE: one in country A, subject to taxation with tax rate $t_{A}$, producing intermediate product $\mathrm{A}$, which is fully supplied to the second division, residing in country $\mathrm{B}$, producing final product $\mathrm{B}$ and being taxed with tax rate $t_{B}, t_{A}<t_{B}$.

7. Price elasticities of supply and demand on the market of the final product are constant.

8. Cost functions of all market participants on the supply side at the particular market are the same and convex in the whole domain. Cost functions can differ by taxation. Average costs of MNE divisions are denoted $c_{A}, c_{B}$.

9. We do not know anything about existence of the market for intermediate product.

10. Transfer prices observable to tax authorities can differ from the real ones due to backward transfers of profits corresponding to over- or underpricing of intermediate product.

11. Revenue authority sensitivity to tax evasive transfer pricing grows linearly with the relative size of difference between transfer price and arms-length price.

12. Penalization for tax evasion is linear with respect to size of tax evasion.

13. Double taxation avoidance treaty between tax authorities in countries $\mathrm{A}$ and $\mathrm{B}$ exists.

14. For simplicity let us assume that transformation of intermediate product into final product is $1: 1$.

15. Capital employed, thus cost of capital expressed in currency units (at divisions $\mathrm{A}$ and $\mathrm{B}$ these are $i_{A}$ and $i_{B}$ ) do not depend on quantity produced, at least in short term.

16. Profit function is continuous and concave in the whole domain. 
17. If transfer pricing positively affects tax base reported in one country, no reward or advantage in that country is given to MNE in exchange. Only negative enforcement (penalization) is used.

18. If not stated otherwise, we analyze MNE and tax authority in short term, i.e. do not assume that part of the profit gained due to evaded tax could be used to increase capital endowment and thus to increase competitive advantage.

19. Market for the final product is perfectly competitive or takes form of monopolistic competition. All producers of final product have the same cost functions, except for cost induced by taxation.

20. Arms-length price of the intermediate product can be obtained from the market, i.e. it does not depend on quantity produced by MNE.

The profit functions at quantity produced $q$ represent the after-tax profit of each division:

$$
\begin{aligned}
& \prod_{A}=q \cdot\left(p_{T}-c_{A}\right) \cdot\left(1-t_{A}\right)-i_{A} \\
& \prod_{B}=q \cdot\left(p_{B}-c_{B}-p_{T}\right) \cdot\left(1-t_{B}\right)-i_{B}
\end{aligned}
$$

If transfer price differs from proper (arms-length) price, then penalty $\Phi_{B}$ in country B can be expected, where $\phi_{B}$ is ratio of penalty to difference between transfer price and arms-length price, times a constant probability (chance) of penalization. We consider this probability constant with respect to a percentage of tax evasion expressed as share on $p_{A L}$. To get the expected penalty we have to multiply $\phi_{B}$ with $d^{2}-d$ once used as base for penalization and the second time as argument of probability of penalization. We could use any other function strictly growing in $d$, to represent probability of penalization, but $d$ is more convenient. The assumption that the cost of tax base manipulation is convex "is standard in the literature on both tax evasion and profit shifting" as (Stöwhase, 2005 , p. 180) notes. If we used another strictly growing function of $d$ for probability of penalization, our conclusions would hold. We consider this design to be close to reality, because with size of tax evasion grows both size of penalty and chance of penalization. Let us assume $\phi_{B} \in[0 ; \infty)$ with respect to $q$ and $d$. If we defined the transfer price $p_{T}$ based on 
difference from non-negative arms length price (intermediate product is not inferior good) $p_{A L} \in[0, \infty)$ as $p_{T}=p_{A L} \cdot(1+d), d \in[0, \infty)$, then

$$
\Phi_{B}=q \cdot p_{A L} \cdot \phi_{B} \cdot d^{2}
$$

Because of $t_{A}<t_{B}$, we can expect that $p_{T}-p_{A L}>0$, thus penalty in country A would be zero as we do not assume any reward for transfer pricing positively affecting tax base. Equation (3) also satisfies the condition of concavity of profit function of MNE in transfer price, because profit of MNE is

$$
\prod_{M N E}=\prod_{A}+\prod_{B}-\Phi_{B}
$$

Moreover we do not assume change in capital or labor endowment, i.e. cost and revenue functions of MNE, excluding tax evasion, are the same as at the other companies. Let us denote $\prod_{X}$ profit function of any producer of the final and intermediate product that is not MNE (remember that they produce both in one company). Then profit function of MNE is sum of profit of non-MNE at the given level of production and result of tax optimization (incl. penalty). To stress dependence on variables we write them down in the following formula:

$$
\prod_{M N E}(q, d)=\prod_{X}(q)+q \cdot p_{A L} \cdot\left[d \cdot\left(t_{B}-t_{A}\right)-\phi_{B} \cdot d^{2}\right]
$$

We could include future consequences like higher probability of future tax controls or discounting future possible penalties, but that would indeed only result in multiplication of (3) by some constant (if we do assume constant discount rate and constant probability of future tax controls at particular level of per unit tax evasion relative to proper price.

\section{How does transfer price influence quantity produced?}

MNE maximizes its profit according to $d$, and $q$. Question is whether quantity produced or arms-length price is function of level of tax evasion $d$. Size of $d$ surely influences optimal quantity produced, i.e. it influences quantity, at which MNE maximizes its profit. But in this case we assume both of them as parameters, which are chosen by MNE. Moreover we cannot say that in general $q$ is function of $d$, and also profit of non-MNE should not be influenced by level of tax evasion. Therefore 
the necessary conditions for finding profit extremes (as profit function of MNE is purely concave, we are finding profit maximum) are:

$$
\begin{aligned}
& \frac{\partial \prod_{M N E}}{\partial d}=q \cdot p_{A L} \cdot\left(t_{B}-t_{A}-\phi_{B} \cdot 2 d\right)=0 \\
& \frac{\partial \prod_{M N E}}{\partial q}=\frac{\partial \prod_{X}}{\partial q}+p_{A L} \cdot\left[d \cdot\left(t_{B}-t_{A}\right)-\phi_{B} \cdot d^{2}\right]=0
\end{aligned}
$$

We omit the possibility that $q=0$. After expressing $d$ in (6)

$$
d=\frac{t_{B}-t_{A}}{2 \cdot \phi_{B}}
$$

and substituting the result instead of $d$ in (7) it is evident that MNE produces above-optimal quantity of final goods, compared to non-MNE, because MNE's optimum is at point, where first derivative of profit function of non-MNE is negative, thus profit function of non-MNE is falling at that point.

$$
\frac{\partial \prod_{X}}{\partial q}=-p_{A L} \cdot \frac{\left(t_{B}-t_{A}\right)^{2}}{4 \cdot \phi_{B}}
$$

Thus possibility of tax evasive transfer pricing inflates international trade above natural levels, to the detriment of governments and nonMNEs in countries with high corporate income tax rates. This result fits empirical observations, e.g. by (Clausing, 2006). Penalization or tightening of transfer pricing rules just puts it back where it should be, i.e. moves MNE optimal production quantity towards optimum, which would be reached if no tax evasion occurred, as is evident from (9). We consider this as side-result of our study, as we are mainly looking for answer of a question whether profit-shifting could be resolved by penalization.

\section{Is there an optimal penalty?}

A question is whether by setting certain level of penalty we could achieve Pareto-efficient equilibrium when tax authorities do not cooperate. That would mean that no further improvement is possible (i.e. total utility, possibly expressed in monetary terms is maximal). If first 
derivatives of any utility function according to $\phi_{B}$ are negative at that point, then at that point everybody within the examined system is losing, when coming closer to equilibrium, such state is therefore not Paretoefficient. In our paper, tax heaven is outside the examined system. In following paragraphs we examine whether there is an optimal solution. In the case of non-cooperative game of tax authority and MNE it is the existence of maximum in function of tax authority income $I_{B}$. In the case of possibility of tradeoff between MNE and tax authority in country B we would be looking for extreme in function $\prod_{M N E}+I_{B}$.

The higher penalty $\phi_{B}$ for given $t_{B}-t_{A}$, the higher also $\partial \prod_{X} / \partial q$. That means that on concave profit function we are moving towards lower production if penalty is increased, ceteris paribus, or formally $\partial q / \partial \phi_{B}<0$. Substituting (8) in (5) yields

$$
\prod_{M N E}=\prod_{X}+q \cdot p_{A L} \cdot \frac{\left(t_{B}-t_{A}\right)^{2}}{4 \cdot \phi_{B}}
$$

We can see that level of penalty causes $\prod_{M N E}$ to decrease asymptotically towards $\Pi_{X}$, which means that derivative of $\prod_{M N E}$ according to $\phi_{B}$ will be negative and asymptotically approaching zero. Differentiating $\prod_{M N E}$ according to $\phi_{B}$ we get after some rearrangement

$$
\frac{\partial \prod_{M N E}}{\partial \phi_{B}}=\frac{\partial \prod_{X}}{\partial \phi_{B}}+p_{A L} \cdot \frac{\left(t_{B}-t_{A}\right)^{2}}{4 \cdot \phi_{B}} \cdot\left(\frac{\partial q}{\partial \phi_{B}}-\frac{q}{\phi_{B}}\right)
$$

$\partial \prod_{M N E} / \partial \phi_{B}$ is negative for every $\phi_{B}$, as both summands are negative (as evident from above text). Because $\partial q / \partial \phi_{B}$ is negative (cp. (9) and subsequent comments), but $q$ positive and the first main multiplicand is positive, we do not know whether (14) is positive or negative, unless we will be able to estimate whether $\left|\partial q / \partial \phi_{B}\right|>q / \phi_{B}$ or the opposite. It is highly probable that $\left|\partial q / \partial \phi_{B}\right|<q / \phi_{B}$ and provable that $\left|\Delta q / \Delta \phi_{B}\right|<q / \phi_{B}$ for $\Delta \phi_{B}=\phi_{B}$, because increasing penalty would shift quantity down very little (just to the optimal quantity of non-MNE) compared to total quantity produced. 
Let us introduce function of corporate income tax (levied in country B) $I_{B}$, incl. $\Phi_{B}$, which consists of tax income from MNE and tax income from other companies (non-MNEs). If the quantity sold in total at the market for final product was $Q$ and we neglected that MNE produces slightly higher quantity than would be optimal, if it did not evade tax, we could write

$$
I_{B}=t_{B} \cdot Q \cdot\left(p_{B}-c_{B}-p_{A L}\right)-t_{B} \cdot q \cdot d \cdot p_{A L}+\Phi_{B}
$$

After substituting (3) and (8) into (12) we get

$$
I_{B}=t_{B} \cdot Q \cdot\left(p_{B}-c_{B}-p_{A L}\right)-q \cdot p_{A L} \cdot \frac{\left(t_{B}+t_{A}\right) \cdot\left(t_{B}-t_{A}\right)}{4 \cdot \phi_{B}}
$$

Profit, which would be achieved if arms length price were used instead of transfer price, does not need attention, at least price and transfer price. If MNE produced less due to penalization for tax-evasive transfer pricing, other non-MNEs will increase production, thus creating profit. Because there is lot of non-MNEs and one MNE and cost functions of them all are the same, there will be larger increase of profit of nonMNEs, than decrease of taxable profit of MNE, if the transfer price used by MNE stayed the same. That is because per unit profit of MNE, taxed in $\mathrm{B}$ is lower than per unit profit of non-MNE. Transfer price decreases with increase of $\phi_{B}$ and it further increases the positive effect from increasing penalization. Finally there is a negative effect of increasing $\phi_{B}$ on total penalty, because $\partial \Phi_{B} / \partial \phi_{B}<0$. Supposing that differential of $t_{B} \cdot Q \cdot\left(p_{B}-c_{B}-p_{A L}\right)$ according to $\phi_{B}$ is zero, we get after some rearrangements

$$
\frac{\partial I_{B}}{\partial \phi_{B}}=p_{A L} \cdot \frac{\left(t_{B}+t_{A}\right) \cdot\left(t_{B}-t_{A}\right)}{4 \cdot \phi_{B}} \cdot\left(\frac{q}{\phi_{B}}-\frac{\partial q}{\partial \phi_{B}}\right)
$$

Thus $\partial I_{B} / \partial \phi_{B}>0$ (for argumentation about relation between $\partial q / \partial \phi_{B}$ and $q / \phi_{B}$ see above). If there were possibility of tradeoff between tax authority in country B and MNE, we would need to find an extreme in $\prod_{M N E}+I_{B}$ (using first-order condition): 


$$
\frac{\partial \prod_{M N E}+I_{B}}{\partial \phi_{B}}=\frac{\partial \prod_{X}}{\partial \phi_{B}}+p_{A L} \cdot \frac{t_{A} \cdot\left(t_{B}-t_{A}\right)}{2 \cdot \phi_{B}} \cdot\left(\frac{q}{\phi_{B}}-\frac{\partial q}{\partial \phi_{B}}\right)=0
$$

The first summand is negative, the second one positive. Although probably the second summand is greater than absolute value of the first one, we need to be sure. Therefore we have to run experiment (simulation). We have to note that we have omitted the possibility of corner solution $\left(\Pi_{B}=0\right)$, which would occur if penalty $\phi_{B}$ were sufficiently low so that it pays to MNE to evade all the corporate income tax in country B. Then could be $\partial I_{B} / \partial \phi_{B}<0$. This is not the real world case as tax authority in country B would probably immediately increase $\phi_{B}$ to decrease tax avoidance. We will reflect that by appropriate setting of $\phi_{B}$ in simulation so that corner solution would not occur.

If $t_{A}$ was sufficiently low (let us say in some tax heaven), the positive effect of the right summand could be too low to prevail over the negative effect of the left summand $\left(\partial \prod_{X} / \partial \phi_{B}\right)$, especially because in such case the negative effect of $\partial \prod_{M N E} / \partial \phi_{B}$ is quite strong and can prefail the positive effect of (14) on (15). We can see that

$$
\frac{\partial \prod_{X}}{\partial \phi_{B}}=\frac{\partial q}{\partial \phi_{B}} \cdot \frac{\partial \prod_{X}}{\partial q}
$$

which turns after substituting (9) instead of $\partial \prod_{X} / \partial q$ and some rearrangements into

$$
\frac{\partial \prod_{M N E}}{\partial \phi_{B}}=-q \cdot p_{A L} \cdot \frac{\left(t_{B}-t_{A}\right)^{2}}{4 \cdot \phi_{B}^{2}}=-q \cdot p_{A L} \cdot d^{2} .
$$

If we left the assumption that market for the final product is either perfectly competitive or monopolistic competition, then we could not omit the effect of stronger enforcement on quantity produced. Furthermore we would have to consider the case, when penalty is too high so that it could cause MNE's company B go bankrupt. If company B filed for bankruptcy, it would take some time at monopolistic, oligopolistic or duopolistic market to recover the quantity produced before company B's bankruptcy. It is also possible that such draconic 
penalty would be presented as intentional liquidation of some business. These possibilities have naturally such consequence that country B loses some tax income - for quite a long time or permanently. Then for high enough $\phi_{B}$ we could probably find maximum of $I_{B}$.

\section{Possibility of collusive behavior between MNE and tax authority}

As we have mentioned above, we would like to examine whether we could find an extreme (not corner solution) of function $\prod_{M N E}+I_{B}$. Unfortunately analysis gave us no decisive solution, thus we have to run simulation. A simulation with the following (usually assumed) properties of the cost and revenue functions was conducted: cost functions are convex, positive in the whole domain; the function of price of the final product is falling in the whole domain (i.e. having negative first derivative). The shape of cost functions used were

$$
\begin{aligned}
& c_{A}(q)=x_{1, A} \cdot q^{2}+x_{2, A} \cdot q+x_{3, A} ; x_{1, A}, x_{2, A}, x_{3, A} \in \mathfrak{R}^{+} \\
& c_{B}(q)=x_{1, B} \cdot q^{2}+x_{2, B} \cdot q+x_{3, B} ; x_{1, B}, x_{2, B}, x_{3, B} \in \mathfrak{R}^{+} \\
& p_{B}(q)=-x_{1, P} \cdot q^{2}+x_{2, P} ; x_{1, P}, x_{2, P} \in \mathfrak{R}^{+}
\end{aligned}
$$

and parameters are chosen so that the profit function was positive for some $q$ and concave in the whole domain. In line with the previous analysis we have assumed that tax authority in country B uses comparable uncontrolled price method to determine the proper transfer price. We assume that tax authority uses price equal to the minimal cost of intermediate product of non-MNE as CUP, because that is what tax authority could derive from market, regardless of quantity produced by individual producer. We assume the profit margin of non-MNE randomly split. The part of non-MNE profit attributed at minimal cost of intermediate product is denoted $\beta$.

We assume that parameters $\beta, t_{A}, t_{B}, x_{i, j}, \phi_{B} ; i \in\{1,2,3\}, j \in\{A, B, P\}$ are random variables (random functions) with normal distribution, values of which were generated in MS Excel 2000 via standard function RAND() by formula 


$$
u=\text { mean }+ \text { range }\left(\frac{\sum_{1}^{12} R A N D(.)-0.5}{12}\right)
$$

where $u$ could be considered - due to Central limit theorem - as observation of random variables with normal distribution. RAND(.) function generates numbers from 0 to 1 with uniform distribution. Value of parameters mean and range for each random variables $m_{k}, \mu_{k}, \beta, t_{A}, t_{B}, x_{i, j}, \phi_{B}$ used in simulation are in Tab. 1 . The random $u$ and high number of simulations $(20000)$ provides that results are quite representative for real world cases.

The simulation was designed in the way that we have generated random $\beta, t_{A}, t_{B}, x_{i, j}, \phi_{B}$ as described above, and found the profitmaximizing volume of production and tax-maximizing volume of production. In each simulation round $\phi_{B}, \beta$ were constant with respect to quantity produced. Maximum of profit MNE has been found in each round of simulation as maximal value of profit in 2-dimensional matrix of MNE profits, where one dimension was $d \in[0,0.4]$, growing with step 0.005 and the other $q \in[18,43]$ growing with step 0.2 (we assume some fluent production of indefinitely divisible product like concrete or gas). We have looked for the extreme of function $\prod_{M N E}+I_{B}$ using $\Delta\left(I_{B}+\prod_{M N E}\right) / \Delta \phi_{B}$ as approximation of $\partial\left(I_{B}+\prod_{M N E}\right) / \partial \phi_{B}$. We have computed that value using maximal profit (profit-maximizing quantity) both for $d$ closest (lower to) $d$ at which maximum of $\prod_{M N E}$ was reached and for the latter one ( $d$ at which maximum of $\prod_{M N E}$ was found). This way we simulate the optimization process of MNE, which accommodates to higher $\phi_{B}$ by decreasing $d$. Profit-shifting used by MNE was constrained by assumption that negative tax base does not lead to negative taxation, i.e. tax was at lest 0 in each country. We have run 20000 such simulations.

Tab. 2 summarizes the results of the simulation. The results of simulation have shown that the range of possible production (18 to 43 
units) was sufficient as there were no results outside this range. The following results of simulation were remarkable:

1. $\partial\left(I_{B}+\prod_{M N E}\right) / \partial \phi_{B}$ was positive for any combination of parameters, as predicted,

2. $\partial \prod_{M N E} / \partial \phi_{B}$ distribution has significantly higher kurtosis than $\partial I_{B} / \partial \phi_{B}$, which is caused by possibility of MNE to adjust quantity produced and relative size of tax evasion $(d)$ to $\phi_{B}$,

3. $\partial \prod_{M N E} / \partial \phi_{B}$ was negative for every combination of parameters, as predicted analytically,

4. $\partial I_{B} / \partial \phi_{B}$ was positive for every combination of parameters, as predicted analytically,

5. $\partial\left(I_{B}+\prod_{M N E}\right) / \partial \phi_{B}$ depends on $\quad \phi_{B}$ so that $\partial\left(I_{B}+\prod_{M N E}\right) / \partial \phi_{B}$ asymptotically approaches 0 with higher $\phi_{B}$ (see Fig. 1) as can be intuitively seen on (15),

6. tax-maximizing quantity of production differs from profitmaximizing quantity if no tax evasion (no profit shifting via transfer prices) is assumed - comparable uncontrolled price method has potential to distort the view of tax authority about activity of MNE.

Tab. 1: Descriptive statistics of the generated input variables by simulation

\begin{tabular}{|c|c|c|c|c|c|c|c|c|}
\hline \multicolumn{3}{|c|}{ Parameters of $\boldsymbol{u}$} & \multicolumn{5}{c|}{ Descriptive statistics of the generated input } \\
variables by simulation \\
\hline $\begin{array}{c}\text { Vari- } \\
\text { able }\end{array}$ & mean & range & $\begin{array}{c}\text { Ave- } \\
\text { rage }\end{array}$ & $\begin{array}{c}\text { Me- } \\
\text { dian }\end{array}$ & Min & Max & $\begin{array}{c}\text { Std. } \\
\text { dev. }\end{array}$ & $\begin{array}{c}\text { Skew- } \\
\text { ness }\end{array}$ \\
\hline$t_{A}$ & 0.200 & 0.400 & 0.200 & 0.200 & 0.079 & 0.317 & 0.033 & -0.033 \\
\hline$t_{B}$ & 0.350 & 0.400 & 0.350 & 0.350 & 0.222 & 0.465 & 0.033 & -0.001 \\
\hline$x_{1, A}$ & 0.030 & 0.040 & 0.030 & 0.030 & 0.016 & 0.042 & 0.003 & 0.002 \\
\hline$x_{2, A}$ & -1.000 & 0.800 & -1.001 & -1.001 & -1.292 & -0.768 & 0.067 & -0.001 \\
\hline
\end{tabular}




\begin{tabular}{|c|r|r|r|r|r|r|r|r|}
\hline \multicolumn{3}{|c|}{ Parameters of $\boldsymbol{u}$} & \multicolumn{5}{|c|}{ Descriptive statistics of the generated input } \\
variables by simulation \\
\hline $\begin{array}{l}\text { Vari- } \\
\text { able }\end{array}$ & mean & range & $\begin{array}{l}\text { Ave- } \\
\text { rage }\end{array}$ & $\begin{array}{l}\text { Me- } \\
\text { dian }\end{array}$ & Min & Max & $\begin{array}{l}\text { Std. } \\
\text { dev. }\end{array}$ & $\begin{array}{l}\text { Skew- } \\
\text { ness }\end{array}$ \\
\hline$x_{3, A}$ & 105.000 & 20.000 & 105.009 & 105.013 & 99.362 & 111.294 & 1.667 & 0.001 \\
\hline$x_{1, B}$ & 0.030 & 0.040 & 0.030 & 0.030 & 0.016 & 0.042 & 0.003 & -0.007 \\
\hline$x_{2, B}$ & -1.000 & 0.800 & -1.000 & -1.000 & -1.230 & -0.756 & 0.067 & -0.008 \\
\hline$x_{3, B}$ & 105.000 & 20.000 & 105.004 & 104.996 & 99.031 & 111.574 & 1.675 & -0.010 \\
\hline$x_{2, P}$ & 250.000 & 100.000 & 249.943 & 249.956 & 221.684 & 280.547 & 8.370 & -0.002 \\
\hline$x_{1, P}$ & 0.300 & 0.400 & 0.300 & 0.300 & 0.166 & 0.432 & 0.033 & 0.016 \\
\hline$\beta$ & 0.500 & 1.000 & 0.501 & 0.501 & 0.204 & 0.800 & 0.083 & -0.011 \\
\hline$\phi_{B}$ & 1.000 & 1.600 & 1.000 & 1.000 & 0.490 & 1.484 & 0.133 & 0.016 \\
\hline
\end{tabular}

Tab. 2: Difference between tax-optimal quantity of production and profit-optimal quantity of production expressed as percentage of profit-optimal quantity

\begin{tabular}{|c|r|c|c|r|r|r|r|}
\hline Variable & $\begin{array}{l}\text { Ave- } \\
\text { rage }\end{array}$ & $\begin{array}{c}\text { Me- } \\
\text { dian }\end{array}$ & Min & Max & $\begin{array}{c}\text { Std. } \\
\text { dev. }\end{array}$ & $\begin{array}{c}\text { Skew- } \\
\text { ness }\end{array}$ & $\begin{array}{c}\text { Kurto- } \\
\text { sis }\end{array}$ \\
\hline$\partial \prod_{M N E} / \partial \phi_{B}$ & -1.533 & -1.140 & -74.674 & 0.000 & 2.730 & -12.247 & 216.167 \\
\hline$\partial I_{B} / \partial \phi_{B}$ & 52.029 & 48.628 & -3.567 & 201.637 & 21.379 & 1.191 & 2.973 \\
\hline$\partial\left(I_{B}+\prod_{M N E}\right) / \partial \phi_{B}$ & 50.496 & 47.260 & -20.037 & 201.145 & 20.591 & 1.138 & 2.741 \\
\hline $\mathrm{Q}_{\text {diff }}$ & -0.480 & -0.400 & -3.600 & 2.600 & 0.648 & -0.299 & 1.087 \\
\hline
\end{tabular}

Note: $Q_{\text {diff }}$ is a difference between tax maximizing production and profit maximizing production of MNE, which does not evade tax and uses arms-length price (comparable uncontrolled price method) for pricing its intermediate product.

There were 26 results of simulation, for which $\partial\left(I_{B}+\prod_{M N E}\right) / \partial \phi_{B}=0$ and 3, for which $\partial\left(I_{B}+\prod_{M N E}\right) / \partial \phi_{B}<0$. After closer examination we have seen that the results of simulation, where $\partial\left(I_{B}+\prod_{M N E}\right) / \partial \phi_{B}=0$, had $t_{A}>t_{B}$ so that $t_{A}$ and $t_{B}$ were at the opposite tails of their distribution. This violates our initial assumption $t_{A}<t_{B}$ and our 
simulation model can not deal with this situation. Much more interesting are rare 3 results, where $\partial\left(I_{B}+\prod_{M N E}\right) / \partial \phi_{B}<0$. For all 3 was common that $t_{A}<<t_{B} \quad\left(t_{B}\right.$ was almost threefold $\left.t_{A}\right)$. That has implication for economic policy, because it means that more severe penalization will more probably more heavily hit companies, who purchase or sell through companies located in offshore centers (or rather tax heavens). On the other hand such companies might be most eager to move their business in another country with more friendly approach, because by tightening transfer pricing rules they lose more than is the addition of public services provided by government that is taxing them. From the point of view of economic policy this is the most inconvenient conclusion, because these companies also have the highest incentives (i.e. highest tax rate differential) to shift profits via transfer prices and to use as large mispricing as possible. So it is most desirable to prevent them from such behavior.

\section{Other properties of transfer pricing rules}

OECD (2001) uses several distinguishable transfer pricing methods: comparable uncontrolled price, cost + method, comparable resale price method, profit split method, formulary apportionment method. These methods have different effects on quantity produced, i.e. for some of them tax-maximizing production is different from profit-maximizing production. Moreover the level of taxation (mainly the tax base) is naturally different when using one or another. That creates opportunity of double taxation. We can expect each tax authority (both in importing and in exporting country) to choose transfer pricing method, which would maximize tax levied. Although agreement on resolving transfer pricing disputes has been recently reached in Europe, such disputes can take several years and it poses some risk on companies - compare conclusions of (Raimondos-Møller and Scharf, 2002). The risk of double taxation might create pressure on MNEs to decrease tax base so that they create some cushion in the case that some part of their profits was taxed twice. 
Fig. 1: Dependence of $\partial\left(I_{B}+\prod_{M N E}\right) / \partial \phi_{B}$ at the close neighborhood of maximal $\prod_{M N E}$ on $\phi_{B}$

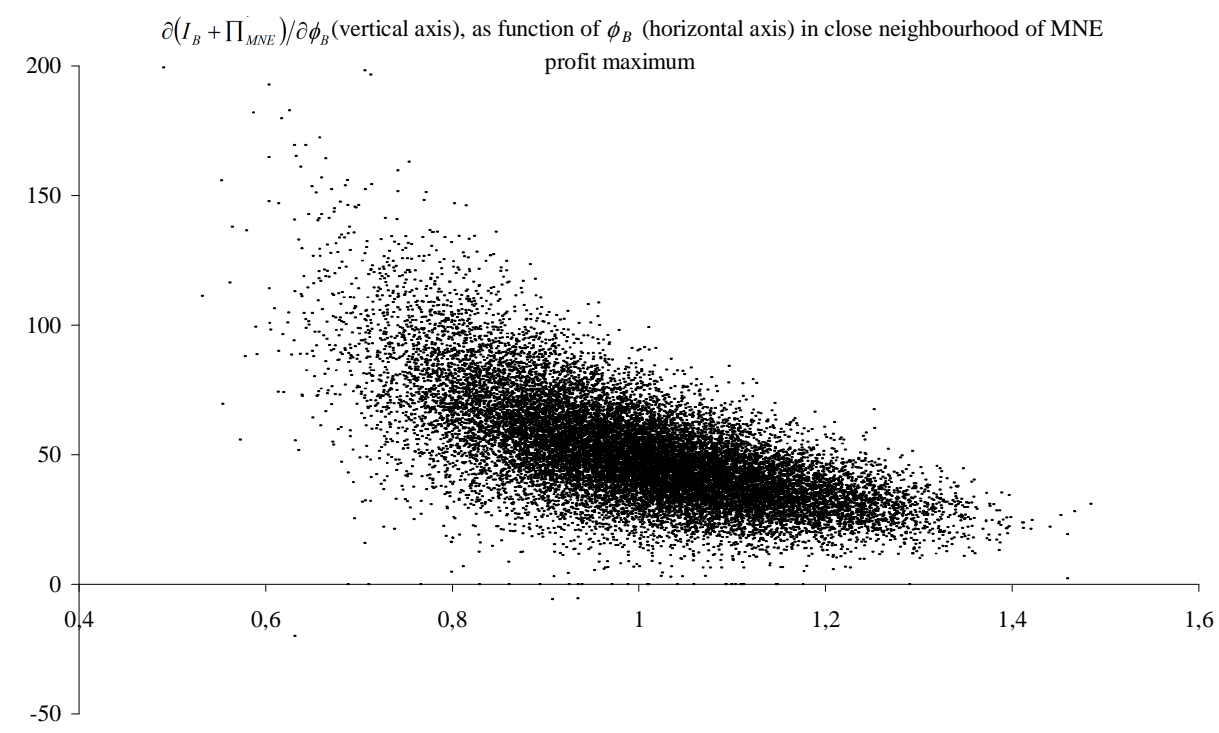

\section{Conclusions and discussion}

We concentrate on usefulness of enforcement of contemporary transfer pricing rules. We have used neoclassical microeconomic apparatus and model with 2 countries, in each of which vertically integrated multinational enterprise has a division. We have found that if market of the product that sells division of multinational enterprise with seat in high tax country is perfectly competitive, then no optimal penalty can be found. That is because more severe enforcement rules (high penalty) do not cause any harm to supply. If tax evading multinational enterprise was brought to bankruptcy by too high penalty, other suppliers would take its place. These conclusions do hold both if tradeoff between tax authority and multinational enterprise were possible and if it was not possible. There would be different situation if the examined markets were oligopolistic or monopolistic - long-term possible loss of taxable profit restricts tax authority from too severe penalties. We have confirmed these findings also by extensive simulation. As a byproduct of our research conducted in this paper we have found that tax rate differentials enable multinationals to exploit market and produce more products than is optimal for a company that can not misuse transfer prices. Even if we did 
not consider use of evaded tax for investments (and getting further competitive advantage), that effect poses important implication for FDI policy. On the other hand multinational enterprises might sometimes feel pushed towards creation of a "tax cushion" as several methods of determination of proper transfer price exist and tax authorities at both sides of the transaction might require use of the method that brings them the highest possible tax revenue. That would result in double taxation.

If we summarized our findings, the contemporary practice of transfer pricing regulation has several implausible properties and there is a need for another instrument to prevent tax-evasive transfer pricing. That instrument can be either replacing tax competition with tax cooperation and harmonization as Raimondos-Møller and Scharf (2002) propose by harmonizing arms-length price principle. That however meets the problem that arms-length principle use can distort the view of tax authority about activity of MNE as tax-maximizing quantity of production is usually lower than profit-maximizing quantity of production. And again we would need some enforcement, which unfortunately is limited by the fact that arms-length price is interval of prices rather than one single price. Last but not least governments of most countries do many things that look like tax competition, but very few that look like tax harmonization. Another option, which we find much more viable, is a design of tax system that would not be sensitive to shifting of tax base or would not enable such profit shifting.

\section{References}

[1] Amerighi, O. (2008): Transfer Pricing and Enforcement Policy in Oligopolistic Markets. In: Brakman, S. - Garretsen, H. (eds.): Foreign Direct Investment and the Multinational Enterprise. Boston, Massachusetts Institute of Technology, 2008, pp. 117-153.

[2] Baldenius, T. - Melumad, N. D. - Reichelstein, S. J. (2004): Integrating Managerial and Tax Objectives in Transfer Pricing. Accounting Review, 2004, vol. 79, no. 3, pp. 591-615.

[3] Buus, T. - Brada, J. (2008): Economics of Transfer Pricing Reviewed. In: Global Management 2008. Porto, IASK, 2008, s. 68-74.

[4] Clausing, K. A. (2006): International Tax Avoidance and U.S. International Trade. National Tax Journal, 2006, vol. 59, no. 2, pp. 269-287. 
[5] Gatti, J. F. - Grinnell, D. J. - Jensen, O. W. (1997): Replicating a Free Market for Internal Transactions: An Alternative Approach to Transfer Pricing. Journal of Business \& Economic Studies, 1997, vol 3, no 2, pp. 43-62.

[6] Hirshleifer, J. (1956): On the Economics of Transfer Pricing. Journal of Business, 1956, vol. 29, no. 3, pp. $172-184$.

[7] OECD (2001): Transfer Pricing Guidelines for Multinational Enterprises and Tax Administrations. Paris, Organisation for Economic Co-operation and Development, 2001.

[8] Pappas, J. L. - Brigham, E. F. - Hirschey, M. (1983): Managerial Economics. Chicago, Dryden Press. 1983.

[9] Raimondos-Møller, P. - Scharf, K. (2002): Transfer Pricing Rules and Competing Governments. Oxford Economic Papers, 2002, vol. 54, no. 2, pp. 230-246.

[10] Schmallenbach, E. (1908): Über Verrechnungspreise. Zeitschrift für handelswissenschaftliche Forschung, 1908/1909, vol. 3, pp. 165-185.

[11] Stöwhase, S. (2005): Asymmetric Capital Tax Competition with Profit Shifting. Journal of Economics, vol. 85, no. 2, pp. 175-196. 


\title{
Can Profit-shifting be Resolved by Penalization?
}

\author{
Tomáš BUUS - Jaroslav BRADA
}

\begin{abstract}
We examine contemporary practice of transfer pricing rules enforcement in this paper. We have used neoclassical microeconomic framework with transfer price estimated via comparable uncontrolled price method. We have found that if vertically integrated multinational enterprise (MNE) has possibility to evade tax through transfer pricing, then it produces higher quantity of final product, than it would if no possibility of tax evasion existed. Secondly we have found that although nowadays' transfer pricing rules require use of enforcement instruments (penalty), there is no penalty high enough to extinguish tax evasive transfer pricing totally, and if market for the product produced in country with high tax rate is perfectly competitive or there is monopolistic competition, no optimal penalty can be found. That changes at oligopolistic, monopolistic or duopolistic market of that product - there we could find optimal penalty.
\end{abstract}

Key words: Tax evasion; Transfer prices; Multinational enterprises.

JEL classification: D21, D29, G39. 